\title{
The 25th anniversary of the retrograde suction decompression technique (Dallas technique) for the surgical management of paraclinoid aneurysms: historical background, systematic review, and pooled analysis of the literature
}

\author{
Bruno C. Flores, MD, Jonathan A. White, MD, H. Hunt Batjer, MD, and Duke S. Samson, MD \\ Department of Neurological Surgery, University of Texas Southwestern Medical Center, Dallas, Texas
}

\begin{abstract}
OBJECTIVE Paraclinoid internal carotid artery (ICA) aneurysms frequently require temporary occlusion to facilitate safe clipping. Brisk retrograde flow through the ophthalmic artery and cavernous ICA branches make simple trapping inadequate to soften the aneurysm. The retrograde suction decompression (RSD), or Dallas RSD, technique was described in 1990 in an attempt to overcome some of those treatment limitations. A frequent criticism of the RSD technique is an allegedly high risk of cervical ICA dissection. An endovascular modification was introduced in 1991 (endovascular RSD) but no studies have compared the 2 RSD variations.
\end{abstract}

METHODS The authors performed a systematic review of MEDLINE/PubMed and Web of Science and identified all studies from 1990-2016 in which either Dallas RSD or endovascular RSD was used for treatment of paraclinoid aneurysms. A pooled analysis of the data was completed to identify important demographic and treatment-specific variables. The primary outcome measure was defined as successful aneurysm obliteration. Secondary outcome variables were divided into overall and RSD-specific morbidity and mortality rates.

RESULTS Twenty-six RSD studies met the inclusion criteria (525 patients, $78.9 \%$ female). The mean patient age was 53.5 years. Most aneurysms were unruptured $(56.6 \%)$ and giant $(49 \%)$. The most common presentations were subarachnoid hemorrhage $(43.6 \%)$ and vision changes $(25.3 \%)$. The aneurysm obliteration rate was $95 \%$. The mean temporary occlusion time was 12.7 minutes. Transient or permanent morbidity was seen in $19.9 \%$ of the patients. The RSD-specific complication rate was low $(1.3 \%)$. The overall mortality rate was $4.2 \%$, with 2 deaths $(0.4 \%)$ attributable to the RSD technique itself. Good or fair outcome were reported in $90.7 \%$ of the patients.

Aneurysm obliteration rates were similar in the 2 subgroups (Dallas RSD 94.3\%, endovascular RSD 96.3\%, $p=0.33$ ). Despite a higher frequency of complex (giant or ruptured) aneurysms, Dallas RSD was associated with lower RSD-related morbidity $(0.6 \%$ vs $2.9 \%, p=0.03)$, compared with the endovascular RSD subgroup. There was a trend toward higher mortality in the endovascular RSD subgroup $(6.4 \%$ vs $3.1 \%, p=0.08)$. The proportion of patients with poor neurological outcome at last follow-up was significantly higher in the endovascular RSD group $(15.4 \%$ vs $7.2 \%, p<0.01)$.

CONCLUSIONS The treatment of paraclinoid ICA aneurysms using the RSD technique is associated with high aneurysm obliteration rates, good long-term neurological outcome, and low RSD-related morbidity and mortality. Review of the RSD literature showed no evidence of a higher complication rate associated with the Dallas technique compared with similar endovascular methods. On a subgroup analysis of Dallas RSD and endovascular RSD, both groups achieved similar obliteration rates, but a lower RSD-related morbidity was seen in the Dallas technique subgroup. Twenty-five years after its initial publication, RSD remains a useful neurosurgical technique for the management of large and giant paraclinoid aneurysms.

https://thejns.org/doi/abs/10.3171/2017.11.JNS17546

KEYWORDS paraclinoid aneurysm; retrograde suction decompression; Dallas technique; historical background; vascular disorders

ABBREVIATIONS DSA = digital subtraction angiography; $E C A$ = external carotid artery; FDS = flow-diverting stent; ICA = internal carotid artery; RSD = retrograde suction decompression; SAH = subarachnoid hemorrhage; TIA = transient ischemic attack; UTSW = University of Texas Southwestern.

SUBMITTED March 3, 2017. ACCEPTED November 4, 2017.

INCLUDE WHEN CITING Published online May 4, 2018; DOI: 10.3171/2017.11.JNS17546. 
$\mathrm{C}$ EREBRAL aneurysms involving the proximal segment of the intracranial internal carotid artery (ICA) are rare. The most accurate number appears to be the one reported in the Cooperative Study of Intracranial Aneurysms and Subarachnoid Hemorrhage, which found 143 of these aneurysms in a series of 2695 cases, for an incidence of 5.4\%.44 These aneurysms are much more common in women, more frequently located on the left side, and more prone to multiplicity. ${ }^{67}$

The term "paraclinoid aneurysm" was first used by Stephen Nutik to describe 5 aneurysms with an intradural origin but intracavernous aneurysm sac location. ${ }^{54}$ The modern use of this term was introduced by Heros, who recognized 2 distinct groups: aneurysms arising from the anteromedial aspect of the ICA, in close proximity to the origin of the ophthalmic artery; and aneurysms arising from the posterolateral portion of the ICA. ${ }^{35}$ With the advent of the operating microscope and microsurgical techniques in the early 1960s, there was a rapid paradigm shift from primary cervical carotid ligation to direct microsurgical clipping for the treatment of paraclinoid aneurysms. ${ }^{9,18,32,33}$ Nonetheless, several anatomical factors intrinsic to paraclinoid aneurysms (i.e., frequent large/ giant aneurysm size, high incidence of atherosclerotic or calcification changes involving aneurysm neck and sac, proximity to the skull base, inability to obtain proximal temporary occlusion) were responsible for an initially discouraging experience with their microsurgical treatment. Aneurysms in this location frequently require temporary interruption of local ICA circulation to facilitate safe clipping. Due to brisk retrograde flow through the ophthalmic artery and the cavernous ICA branches, simple trapping of the cervical and communicating segment of the supraclinoid ICA is often inadequate to soften the aneurysm, particularly in cases of large or giant lesions.

In 1981, Flamm published the first technical note on direct aneurysm puncture for suction decompression. It had the disadvantage of introducing a relatively large instrument (no. 21 butterfly-type scalp vein needle) into an already limited operative field. ${ }^{23}$ It also necessitated continuous suction application over the needle tubing by the neurosurgeon's nondominant hand, severely limiting their bimanual abilities. To overcome those limitations, in 1990 the senior authors (H.H.B. and D.S.S.) described the retrograde suction decompression (RSD) technique for treatment of paraclinoid aneurysms, or what was later popularized as the "Dallas technique." It consisted of temporary trapping of the ICA at its proximal cervical and supraclinoid segments, direct cervical ICA puncture with a no. 18 angiocatheter, and aneurysm deflation by retrograde suction aspiration (Fig. 1).

Over the last 25 years, the Dallas RSD technique has been frequently applied to the microsurgical treatment of complex paraclinoid ICA aneurysms at our institution and other cerebrovascular referral centers in the US and abroad. $7,16,20,22,48,55,56,68,73-75,78-81$ One of the most frequent criticisms of the Dallas RSD technique was derived from an alleged high risk of cervical ICA injury, potentially resulting in vessel dissection/occlusion, intracranial thromboembolic complications, or large hemispheric ischemic stroke. In 1991, Scott et al. introduced an endovascular modification of the Dallas RSD technique (endovascular RSD) ${ }^{65}$ It consisted of a transfemoral introduction of a 5-Fr double-lumen balloon occlusion catheter into the distal cervical ICA for temporary vessel occlusion, intracranial supraclinoid surgical ICA trapping, and RSD using a 20-ml syringe. This technique obviates the need for cervical ICA dissection, but introduces a new complication profile with the need for systemic heparinization, the need for heparinized saline flushes through the catheter, the possibility of ICA injury from catheter manipulation or balloon inflation, the need for angiography-equipped operating room suites, etc.

Several authors have described their experience with the Dallas RSD and the endovascular RSD. 4,7,8,12,16,20-22,27, $28,34,36,42,48,49,52,55-57,65,68,73-75,78,80,81$ None, however, have compared those 2 RSD technical variations to assess for specific risk profiles and procedural-related morbidity. The goals of the current study were to complete a systematic review of the RSD literature as well as a pooled analysis of all the studies using Dallas RSD or endovascular RSD, including their specific obliteration, morbidity, and mortality rates. Lastly, our experience accumulated over the last 25 years at the University of Texas Southwestern (UTSW) Medical Center is briefly reported. This institutional retrospective review was approved by the UTSW institutional review board. Due to the primary focus of the current article on the historical background and literature review of the RSD technique, our institutional experience will be further described in a separately dedicated project.

\section{Methods}

A systematic review of the neurosurgical literature was undertaken using 2 large clinical databases (MEDLINE/ PubMed and Web of Science). Cross-reference terms used for database query included "paraclinoid aneurysm," "paraclinoidal aneurysm," "retrograde suction decompression," and "Dallas technique." All the studies published from 1990 through 2016 in which either Dallas RSD or endovascular RSD were used for treatment of intracranial aneurysms were identified. The references for each of the identified studies were then screened to identify any other pertinent manuscripts that were not captured with the initial search. A final search was then conducted using those 2 databases for identification of all the published articles from 1990 through 2016 in which the original Dallas RSD or endovascular RSD studies were cited. Any study without description of a functional outcome was excluded from the analysis. Data collection and systematic review were undertaken following standard PRISMA guidelines (Fig. 2). ${ }^{50}$

Demographic data (study date, number of patients, mean age, sex) were collected for all the studies. Treatment-specific variables analyzed included aneurysm location, aneurysm size, rupture status, symptoms at presentation, preoperative trial balloon occlusion, aneurysm obliteration rates, and morbidity and mortality rates. Finally, intraoperative categorical variables, such as type of RSD technique (Dallas RSD vs endovascular RSD), intraoperative angiography, aspirated blood volume, and temporary occlusion time, were extracted for data analysis. 

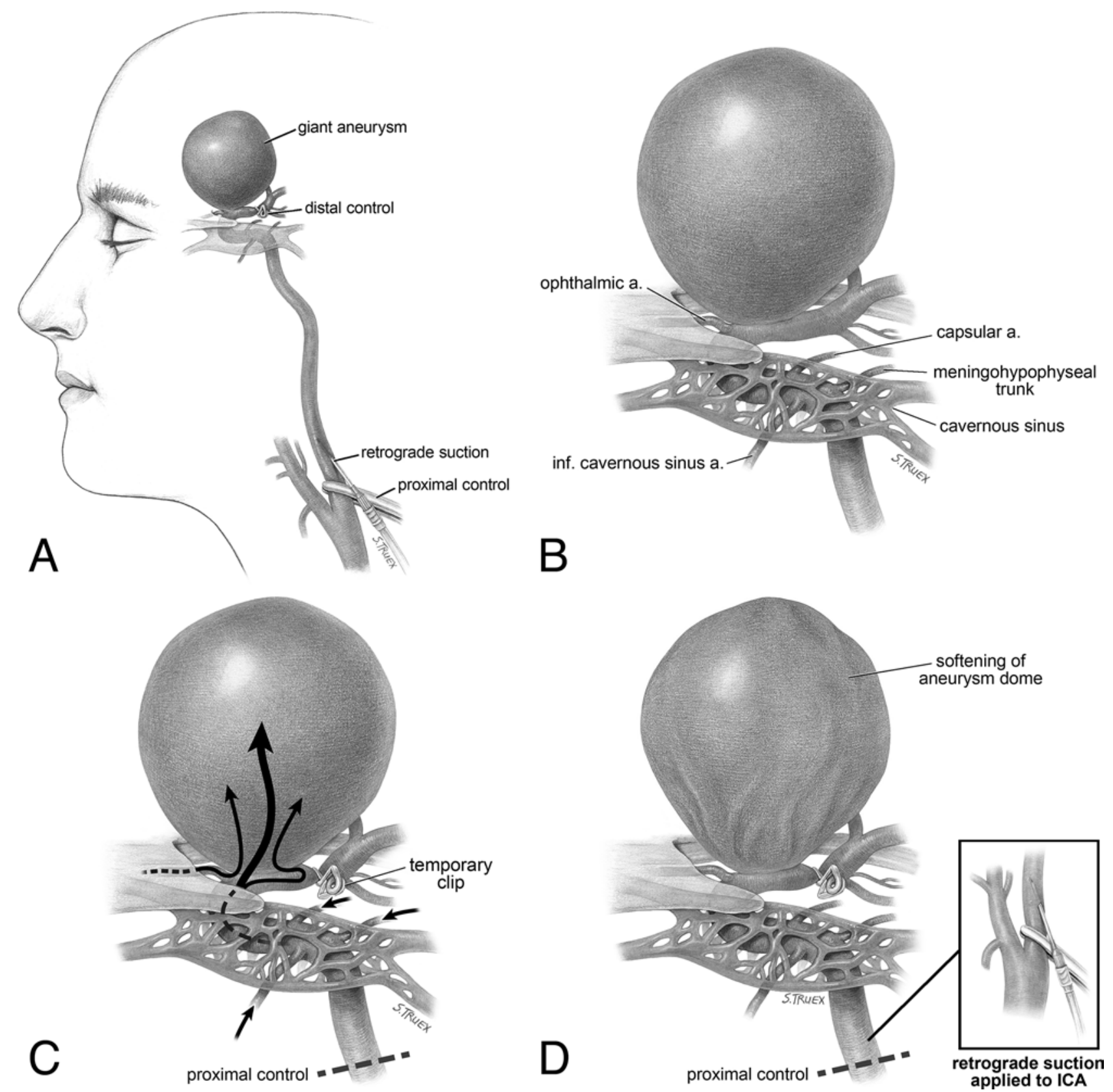

FIG. 1. Artist's illustration of the surgical principles of the RSD technique for treatment of large and giant paraclinoid aneurysms. A: The ICA has been trapped by proximal occlusion at the cervical ICA segment just distal to the bifurcation, and a temporary clip at the supraclinoid ICA just proximal to the origin of the posterior communicating artery. An angiocatheter was introduced on an oblique fashion into the cervical ICA for suction decompression. B: Magnified lateral view of the cavernous and intracranial ICA showing the relationship of the paraclinoid aneurysm with the adjacent cavernous and supraclinoid branches of the internal carotid artery. C: Despite cervical and supraclinoid ICA occlusions, aneurysm turgor is maintained by retrograde filling through the cavernous ICA branches and the ophthalmic artery. D: Retrograde suction is applied through the cervical ICA (right), with resultant transient aneurysm sac deflation. a. = artery; inf. = inferior. Copyright Suzanne Truex. Published with permission.

The primary outcome measure was defined as successful aneurysm obliteration. Secondary outcome variables were divided into overall and RSD-specific morbidity and mortality rates. The latter was used in an attempt to determine any complications documented by the authors that were directly attributed to the RSD portion of the procedure.
Qualitative and quantitative pooled analysis of the RSD data were completed for the whole study group, then stratified for each of the RSD subgroups (Dallas vs endovascular). The frequency of each of the observed variables was calculated, and the weighted proportions and means were obtained based on each study's patient numbers. Due to the intrinsic heterogeneity of the sampled data, all sta- 


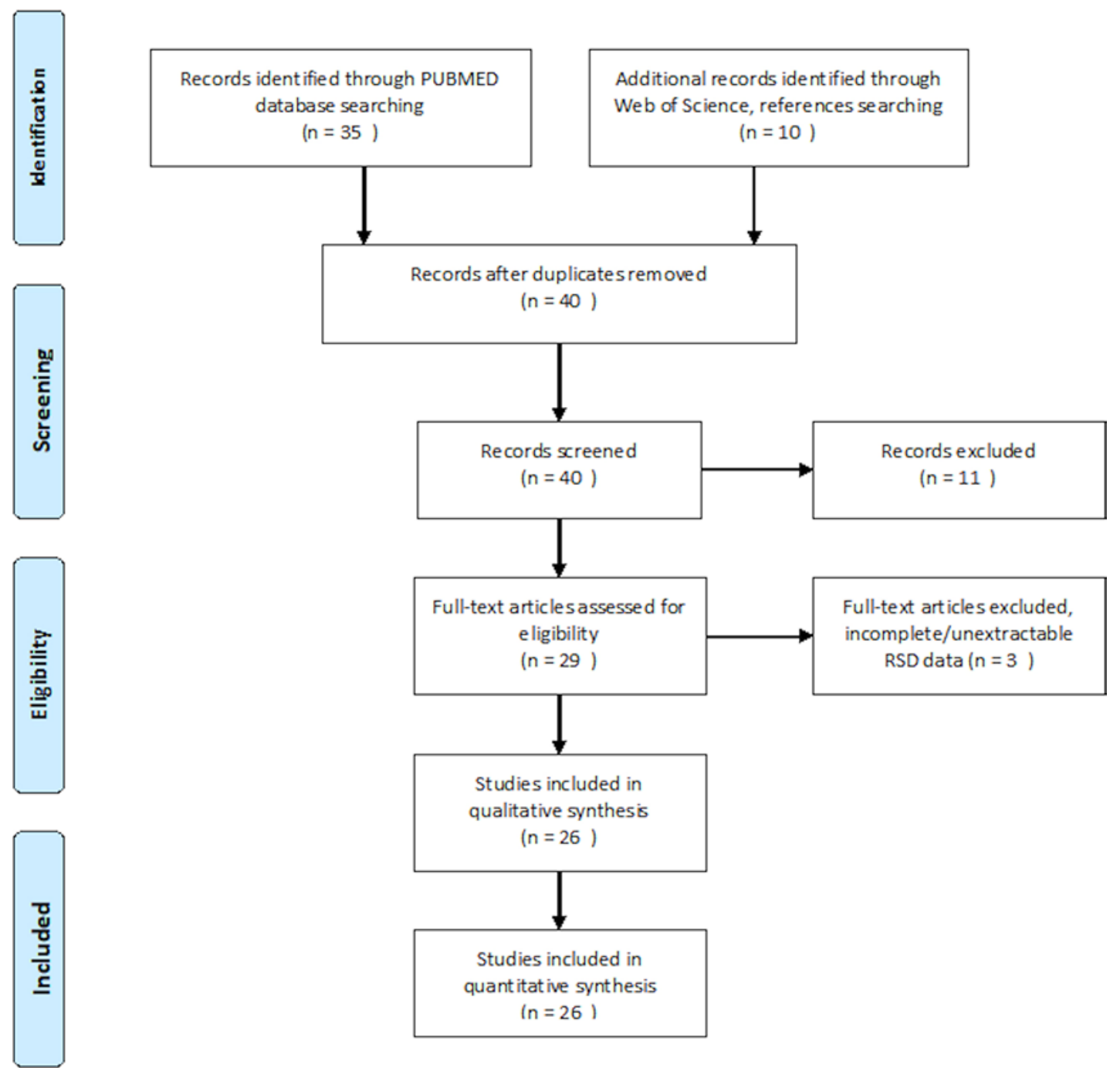

FIG. 2. PRISMA Flow Diagram for the RSD systematic review. Based on template from Moher D, Liberati A, Tetzlaff J, Altman DG, The PRISMA Group: Preferred reporting items for systematic reviews and meta-analyses: the PRISMA statement. PLoS Med 6(7):e1000097, 2009. doi:10.1371/journal.pmed1000097. Figure is available in color online only.

tistical analysis was completed using nonparametric tests, based on a random-effects model. Fisher's exact test was used when appropriate to evaluate categorical variables between the 2 distinct subgroups. The Mann-Whitney Utest was used when appropriate to evaluate continuous or ordinal variables between the 2 RSD groups. A p value of less than 0.05 was established as indicating statistical significance. Two types of commercially available statistical software were used, as indicated (SPSS v. 22 [IBM Corp.] and Review Manager 5 [RevMan 5, Cochrane]).

\section{Results}

Forty-five studies were identified using MEDLINE/ PubMed and Web of Science. Of those, 16 studies were excluded after initial screening, and 29 studies were selected for data review. Three of these 29 studies were excluded from data analysis. ${ }^{34,42,66}$ In all those 3 studies, RSD was applied only on a subgroup of patients, but data-specific parameters exclusive to the RSD patients could not be extracted from the general study populations.

Including the senior authors' initial technical note from $1990,{ }^{8} 26$ studies (14 Dallas RSD, 11 endovascular RSD, 1 mixed) that met the inclusion criteria were identified, for a total of 525 patients (540 paraclinoid aneurysms) (Tables 1 and 2). The mean patient age was $53.5 \pm 6.8$ years. As previously described by several authors, there was a heavy female preponderance (78.9\% of patients). The majority of the aneurysms were unruptured (56.6\%) and of giant size (49\%). The most common presenting signs were subarachnoid hemorrhage (SAH), vision changes, and headaches (Table 3).

Successful aneurysm obliteration was achieved in 95\% of the patients. Aneurysm occlusion was confirmed by intraoperative angiography in $86.3 \%$ of the patients $(79.2 \%$ of the Dallas RSD and 100\% of the endovascular RSD patients) In the remaining $20.8 \%$ of the Dallas RSD patients, the occlusion was confirmed by standard postop- 
TABLE 1. Dallas RSD technique case series-1990-2016

\begin{tabular}{|c|c|c|c|c|c|c|c|c|c|c|}
\hline Authors \& Year & $\begin{array}{c}\text { No. } \\
\text { of } \\
\text { Pts }\end{array}$ & $\begin{array}{l}\text { Mean } \\
\text { Age } \\
\text { (yrs) }\end{array}$ & $\begin{array}{c}\text { Female } \\
(\%)\end{array}$ & $\begin{array}{c}\text { Aneurysm } \\
\text { Size }\end{array}$ & $\begin{array}{c}\text { No. of } \\
\text { Ruptured } \\
\text { Aneurysms }\end{array}$ & $\begin{array}{c}\text { Obliteration } \\
\text { Rate }(\%)\end{array}$ & $\begin{array}{c}\text { Overall } \\
\text { Morbidity } \\
(\%)\end{array}$ & $\begin{array}{c}\text { Overall } \\
\text { Mortality } \\
(\%)\end{array}$ & $\begin{array}{c}\text { RSD } \\
\text { Morbidity } \\
(\%)\end{array}$ & $\begin{array}{c}\text { RSD } \\
\text { Mortality } \\
(\%)\end{array}$ \\
\hline Batjer \& Samson, 1990 & 40 & - & - & $\mathrm{G}(40)$ & - & 100.0 & 0 & 0 & 2.5 & 0 \\
\hline Tamaki et al., 1991 & 4 & 61.0 & 100 & $\begin{array}{l}L(1) \\
G(3)\end{array}$ & 0 & 100.0 & 50 & 0 & 0 & 0 \\
\hline Batjer et al., 1994 & 22 & - & 77.5 & $\mathrm{G}(22)$ & 7 & 100.0 & 4.5 & 4.5 & 0 & 0 \\
\hline Fan et al., 1999 & 2 & 70.0 & - & $\mathrm{G}(2)$ & - & 100.0 & NR & 0 & 0 & 0 \\
\hline Vega-Basulto, 2003 & 15 & 48.0 & 73.3 & $\begin{array}{l}L(3) \\
G(12)\end{array}$ & 14 & 100.0 & 33.3 & 0 & 0 & 0 \\
\hline Xu et al., 2008 & 33 & 51.4 & 58.3 & $\begin{array}{l}L(9) \\
G(27)\end{array}$ & 19 & 100.0 & 24.2 & 6.0 & 0 & 0 \\
\hline Takahashi et al., 2008 & 8 & - & - & $\begin{array}{l}L(N R) \\
\text { G (NR) }\end{array}$ & 0 & 87.5 & 0 & 0 & 0 & 0 \\
\hline Xu et al., 2010 & 51 & 54.5 & 64.7 & $\begin{array}{l}L(24) \\
G(27)\end{array}$ & 37 & 84.0 & 17.6 & 2.0 & 0 & 2.0 \\
\hline Eliava et al., 2010 & $83^{*}$ & 45.5 & 83.1 & $\begin{array}{l}L(23) \\
G(60)\end{array}$ & 48 & 90.4 & 31.2 & 3.6 & 0 & 0 \\
\hline Dehdashti et al., 2012 & 12 & 49.0 & 95.2 & $\begin{array}{l}L(6) \\
G(15)\end{array}$ & 6 & 90.5 & 23.8 & 9.5 & 0 & 0 \\
\hline Mattingly et al., 2013 & 18 & 54.0 & 88.9 & $\begin{array}{l}L(8) \\
G(10)\end{array}$ & 3 & 94.4 & 38.9 & 0 & 0 & 0 \\
\hline Shimizu et al., 2015 & 13 & 55.3 & 84.6 & $\begin{array}{l}L(33) \\
G(6)\end{array}$ & 16 & 94.4 & 53.8 & 0 & 0 & 0 \\
\hline Otani el al., $2016^{55}$ & 23 & 66.0 & 95.7 & $\begin{array}{l}S(2) \\
L(19) \\
G(2)\end{array}$ & 7 & 95.7 & 26.1 & 4.3 & 0 & 0 \\
\hline Otani et al., $2016^{56}$ & 30 & 62.0 & 93.3 & $\begin{array}{l}S(8) \\
L(20) \\
G(2)\end{array}$ & 7 & 96.7 & 20 & 3.3 & 0 & 0 \\
\hline Takeuchi et al., 2016 & 20 & 69.7 & 95.0 & $\begin{array}{l}S(3) \\
L(16) \\
G(1)\end{array}$ & 1 & 100.0 & 30 & 0 & 0 & 0 \\
\hline
\end{tabular}

* 62 Dallas RSD, 21 endovascular RSD cases.

$\mathrm{G}=$ giant; $\mathrm{L}=$ large; $N R=$ not reported; $p$ ts = patients; $S$ = small.

erative digital subtraction angiography (DSA). The mean temporary occlusion time was $12.7 \pm 6.7$ minutes. Only 5 studies reported on the aspirated volume through RSD technique (1 Dallas RSD, 4 endovascular RSD), with wide variation in the recorded numbers (30-500 ml). Systemic heparinization with intravenous heparin bolus prior to the endovascular procedure was described in 6 studies (2 Dallas RSD, 4 endovascular RSD). The catheter was flushed with continuous heparinized saline solution, but without systemic heparinization in 7 studies (2 Dallas RSD, 5 endovascular RSD). In the remaining 13 studies, no information about systemic or catheter-based heparinization was provided by the authors. Transient or permanent morbidity was seen in $19.9 \%$ of the patients. Interestingly, the rate of complications directly attributable to the RSD technique itself was only $1.3 \%$. The overall mortality rate was $4.2 \%$, with 2 deaths $(0.4 \%)$ attributable to the RSD technique itself. Good or fair outcome was reported in $90.7 \%$ of the patients.

Subgroup analysis was conducted for both RSD tech- niques. The endovascular RSD group population was younger (49.8 vs 54 years), had a higher percentage of small aneurysms (16.9\% vs $3.3 \%)$, and a lower percentage of giant aneurysms (34.2\% vs 56\%). The number of SAH patients was higher in the Dallas RSD group (43.9\% vs $33.7 \%)$. Temporary occlusion time was lower in the Dallas RSD group (12.4 vs 13.6 minutes). The 2 groups had similar aneurysm obliteration and overall morbidity rates. However, the rate of RSD-related morbidity (2.9\% vs $0.6 \%, p=0.03$ ) and proportion of patients with poor outcome at last follow-up $(15.4 \%$ vs $7.2 \%, \mathrm{p}<0.01)$ were significantly higher in the endovascular RSD group than in the Dallas RSD group (Table 3). Five patients in the endovascular RSD group had complications that were attributable to the endovascular procedure itself (2 MCA thromboembolic occlusions, 1 ICA occlusion secondary to balloon inflation, 1 ischemic stroke without large vessel occlusion, and 1 ICA dissection). In the Dallas RSD group, 2 patients had complications directly related to the cervical carotid puncture (1 cervical ICA dissection requiring 
TABLE 2. Endovascular RSD technique case series-1990-2016

\begin{tabular}{|c|c|c|c|c|c|c|c|c|c|c|}
\hline Authors \& Year & $\begin{array}{c}\text { No. } \\
\text { of } \\
\text { Pts }\end{array}$ & $\begin{array}{l}\text { Mean } \\
\text { Age } \\
\text { (yrs) }\end{array}$ & $\begin{array}{c}\text { Female } \\
(\%)\end{array}$ & $\begin{array}{l}\text { Aneurysm } \\
\text { Size }\end{array}$ & $\begin{array}{c}\text { No. of } \\
\text { Ruptured } \\
\text { Aneurysms }\end{array}$ & $\begin{array}{c}\text { Obliteration } \\
\text { Rate (\%) }\end{array}$ & $\begin{array}{c}\text { Overall } \\
\text { Morbidity } \\
(\%)\end{array}$ & $\begin{array}{c}\text { Overall } \\
\text { Mortality } \\
(\%)\end{array}$ & $\begin{array}{c}\text { RSD } \\
\text { Morbidity } \\
(\%)\end{array}$ & $\begin{array}{c}\text { RSD } \\
\text { Mortality } \\
(\%)\end{array}$ \\
\hline Scott et al., 1991 & 1 & 41.0 & 100 & L (1) & 0 & 100.0 & 0 & 0 & 0 & 0 \\
\hline Albert et al., 1993 & 2 & 42.0 & 50 & $\begin{array}{l}L(1) \\
N R(1)\end{array}$ & 1 & 100.0 & 0 & 0 & 0 & 0 \\
\hline Mizoi et al., 1993 & 6 & 55.0 & 100 & $\begin{array}{l}L(5) \\
G(1)\end{array}$ & 1 & 100 & 33.3 & 0 & 16.7 & 0 \\
\hline Fahlsbusch et al., 1997 & 3 & 51.3 & 66.7 & G (3) & 0 & 100.0 & 66.7 & 0 & 0 & 0 \\
\hline Arnautović et al., 1998 & 16 & 48.1 & 100 & $\begin{array}{l}L(8) \\
G(8)\end{array}$ & 7 & 93.8 & 50 & 6.25 & 12.5 & 0 \\
\hline $\mathrm{Ng}$ et al., 2000 & 16 & NR & 79.2 & $\begin{array}{l}S(2) \\
L(12) \\
G(10)\end{array}$ & 5 & 91.7 & 0 & 9.0 & 0 & 4.5 \\
\hline Parkinson et al., 2006 & 1 & 51.0 & 100 & $G(1)$ & 0 & 100.0 & 0 & 0 & 0 & 0 \\
\hline Hoh et al., 2008 & 1 & 53.0 & 100 & $L(1)$ & 0 & 100.0 & 0 & 0 & 0 & 0 \\
\hline Fulkerson et al., 2009 & 63 & 50.4 & - & $\begin{array}{l}S(26) \\
L(23) \\
G(14)\end{array}$ & 17 & 98.4 & 15.9 & 9.5 & 1 & 1.6 \\
\hline Eliava et al., 2010 & $83^{*}$ & 45.5 & 83.1 & $\begin{array}{l}L(23) \\
G(60)\end{array}$ & 48 & 90.4 & 31.2 & 3.6 & 0 & 0 \\
\hline Chen et al., 2011 & 27 & 58.8 & 29.6 & $\begin{array}{l}L(22) \\
G(6)\end{array}$ & 5 & 100.0 & 0 & 0 & 0 & 0 \\
\hline Gao et al., 2016 & 15 & 55.2 & 73.3 & $\begin{array}{l}L(10) \\
G(5)\end{array}$ & 6 & 93.3 & 26.7 & 6.7 & 0 & 0 \\
\hline
\end{tabular}

* 62 Dallas RSD, 21 endovascular RSD cases.

emergent thromboendarterectomy, and one ICA occlusion with thromboembolic ischemic stroke).

A trend toward higher overall mortality rates was seen in the endovascular RSD group $(6.4 \%$ vs $3.1 \%, \mathrm{p}=$ 0.08). Two deaths were directly attributable to the RSD technique, one in each RSD group. A 56-year-old woman who was treated successfully for an ophthalmic segment ICA aneurysm died 2 weeks after her operation due to a hemispheric stroke; the authors attributed the death to a possible embolism secondary to cervical carotid artery injury. ${ }^{81}$ The second patient was noted to have near-occlusive thrombus at the supraclinoid ICA on the initial angiography prior to aneurysm clipping. After microsurgical exposure of the supraclinoid ICA, intraluminal thrombus was seen at the ICA terminus and the proximal $\mathrm{M}_{1}$. The aneurysm was successfully clipped, but anterograde flow could not be restored to the ICA, and the patient suffered a fatal MCA ischemic stroke. ${ }^{52}$

Institutional experience at the University of Texas Southwestern Medical Center from 1990 through 2016 identified 124 patients who had undergone treatment of a paraclinoid aneurysm with the assistance of the Dallas RSD technique (Table 4). Their overall age was similar to the pooled analysis, with a slightly higher preponderance of female patients $(86.1 \%)$. Strikingly, $41.9 \%$ of the treated patients were found to have additional intracranial aneurysms. The mean paraclinoid aneurysm size was 17.7 $\pm 7.4 \mathrm{~mm}$. Our obliteration rate-as demonstrated by intra- operative or postoperative DSA - was similar to that found in our pooled analysis (95.2\%). The RSD-related morbidity and mortality rates were $6.5 \%$ and $1.6 \%$, respectively. Good outcome-as measured by the Glasgow Outcome Scale at the last clinic follow-up-was $81.4 \%$. Importantly, half of the patients in whom the paraclinoid aneurysm presented with vision symptoms had improvement in their postoperative vision status by the time of their last followup (data not shown). Table 4 summarizes the descriptive analysis of the UTSW data. As mentioned in the Introduction of the present study, our institutional data will be further detailed on a future separate manuscript.

\section{Discussion}

Surgical capacity is an attitude of mind, manual dexterity is a small but important adjunct. Sometimes courage is required. Courage implies an appreciation of risk - in fact, it implies fear under control. He who knows no fear is not courageous but reckless.

-Prof. Norman Dott, 1897-1973

\section{Historical Background}

The evolution of the surgical treatment of ICA aneurysms represents, in itself, a historical journey into the early years of cerebrovascular neurosurgery. Credit is given to Sir Victor Horsley (1885) as the first surgeon to apply 
TABLE 3. Statistical analysis of 26 studies on RSD technique for the surgical treatment of paraclinoid aneurysms-1990-2016

\begin{tabular}{|c|c|c|c|c|}
\hline Variable & Pooled Analysis & Dallas RSD & Endo RSD & $p$ Value \\
\hline Studies (n) & $26 \dagger$ & 15 & 12 & - \\
\hline Pts (n) & 525 & 353 & 172 & - \\
\hline Aneurysms (n) & 540 & 356 & 184 & - \\
\hline Age (mean) & $53.5 \pm 6.8$ & $54 \pm 7.7$ & $49.8 \pm 6.5$ & $<0.01^{*}$ \\
\hline Sex, female (\%) & 78.9 & 80.4 & 75.4 & 0.19 \\
\hline \multicolumn{5}{|l|}{ Size $(n, \%)$} \\
\hline Small & $44(7.7)$ & $13(3.3)$ & $31(16.9)$ & $<0.01^{*}$ \\
\hline Large & $249(43.3)$ & $159(40.7)$ & $90(48.9)$ & 0.07 \\
\hline Giant & $282(49.0)$ & $219(56.0)$ & $63(34.2)$ & $<0.01^{*}$ \\
\hline Unruptured status (\%) & 56.6 & 50.8 & 66.3 & $0.01^{*}$ \\
\hline Preop TBO (\%) & 80.7 & 68.6 & 62.2 & $0.14^{*}$ \\
\hline \multicolumn{5}{|l|}{ Presentation (\%)‡ } \\
\hline SAH & 43.6 & 49.2 & 33.7 & $0.01^{*}$ \\
\hline Vision changes & 25.3 & 34.4 & 14.0 & $<0.01^{*}$ \\
\hline Headaches & 16.4 & 21.2 & 11.0 & 0.02 \\
\hline TIA/stroke & 2.7 & 2.9 & 2.9 & 0.84 \\
\hline Other & 16.6 & 20.3 & 13.4 & 0.17 \\
\hline Not reported & 8.3 & - & 25.0 & \\
\hline Intraop cerebral protection (\%) & 63.3 & 59.5 & 72.1 & $<0.01^{*}$ \\
\hline Intraop angiography (\%) & 86.3 & 79.2 & 100.0 & $<0.01^{*}$ \\
\hline RSD aspirated vol in $\mathrm{ml}$ (min) & 30 & 30 & 45 & \\
\hline RSD aspirated vol in ml (max) & 500 & 50 & 500 & \\
\hline Temporary occlusion in minutes (mean) & $12.7 \pm 6.7$ & $12.4 \pm 7.2$ & $13.6 \pm 5.6$ & $0.04^{*}$ \\
\hline Obliteration rate $(\%)$ & 95.0 & 94.3 & 96.3 & 0.33 \\
\hline \multicolumn{5}{|l|}{ Morbidity (\%) } \\
\hline Overall (per pt) & 19.9 & 21.2 & 17.5 & 0.32 \\
\hline RSD (per pt) & 1.3 & 0.6 & 2.9 & $0.03^{*}$ \\
\hline \multicolumn{5}{|l|}{ Outcome (\%) } \\
\hline Good & 79.3 & 81.0 & 74.5 & 0.09 \\
\hline Fair & 11.4 & 11.8 & 10.0 & 0.54 \\
\hline Poor & 9.3 & 7.2 & 15.4 & $<0.01^{*}$ \\
\hline \multicolumn{5}{|l|}{ Mortality } \\
\hline Overall (per pt) & 4.2 & 3.1 & 6.4 & 0.08 \\
\hline RSD (per pt) & 0.4 & 0.3 & 0.6 & 0.60 \\
\hline
\end{tabular}

Endo = endovascular; $\max =$ maxiumum; $\min =$ minimum; TBO = trial balloon occlusion.

Mean values are given with SDs.

* Statistically significant.

$\dagger$ One study with both techniques (62 Dallas RSD, 21 endovascular RSD).

$\ddagger$ Some patients had more than 1 symptom at presentation.

the principles of Hunterian ligation for the treatment of an intracranial aneurysm, while operating on a patient with a suspected middle cranial fossa tumor. ${ }^{58}$ In 1931, frustrated by the high rebleeding rates in several of his SAH patients treated medically, Prof. Norman Dott became the first neurosurgeon to treat an intracranial aneurysm by direct aneurysm exposure. Through a left frontal craniotomy, he dissected a proximal left middle cerebral artery aneurysm and successfully wrapped it with muscle graft harvested from the patient's own leg. The patient made an excellent neurological recovery and had no signs of further hemorrhage until he died 11 year later from cardiac causes. ${ }^{43}$ In
1941, Walter Dandy described the first neurosurgical series of supraclinoid ICA aneurysms treated successfully by primary aneurysm clipping or trapping, using a modified version of Harvey Cushing's silver clip. ${ }^{14}$

Despite the then-recent interest in intracranial surgery for aneurysm treatment, the majority of the authors at the time still recognized cervical carotid ligation as the treatment of choice for proximal supraclinoid ICA aneurysms. ${ }^{18,41,77}$ Norlen and Olivecrona recognized, in 1953, that "whether indirect methods, such as ligature of the carotid artery in the neck, or a direct attack on the aneurysm by clipping its neck should be preferred cannot yet 
TABLE 4. The UTSW experience with the use of RSD technique for the surgical treatment of paraclinoid aneurysms-1990-2016

\begin{tabular}{|c|c|}
\hline Variable & Pooled Analysis \\
\hline Pts (n) & 124 \\
\hline Aneurysms (n) & 178 \\
\hline Age (mean) & $55.5 \pm 10.7$ \\
\hline Sex, female $(\%)$ & 86.1 \\
\hline Multiple intracranial aneurysms (\%) & 41.9 \\
\hline Aneurysm size (mean) & $17.7 \pm 7.4$ \\
\hline Small $(n, \%)$ & $17(13.7)$ \\
\hline Large (n, \%) & $69(55.6)$ \\
\hline Giant (n, \%) & $38(30.7)$ \\
\hline Unruptured status (\%) & 72.3 \\
\hline Preop TBO (\%) & 28 \\
\hline \multicolumn{2}{|l|}{ Presentation } \\
\hline SAH (\%) & 27.7 \\
\hline WFNS score (mean) & $2.18 \pm 1.10$ \\
\hline Vision changes (\%) & 46.2 \\
\hline Headaches (\%) & 19.3 \\
\hline TIA/stroke (\%) & 4.2 \\
\hline Other $(\%)$ & 14.3 \\
\hline Preop TBO (\%) & 31.1 \\
\hline Intraop angiography (\%) & 86.3 \\
\hline \multicolumn{2}{|l|}{ Temporary occlusion in minutes } \\
\hline Mean & $22.75 \pm 22.9$ \\
\hline Median & 17.5 \\
\hline Obliteration rate (\%) & 95.2 \\
\hline \multicolumn{2}{|l|}{ Neurological morbidity (\%) } \\
\hline Overall (per pt) & 23.1 \\
\hline RSD (per pt) & 6.5 \\
\hline \multicolumn{2}{|l|}{ Outcome $(\%)$} \\
\hline Good & 81.4 \\
\hline Fair & 9.7 \\
\hline Poor & 8.9 \\
\hline \multicolumn{2}{|l|}{ Mortality } \\
\hline Overall (per pt) & 4.6 \\
\hline RSD (per pt) & 1.6 \\
\hline
\end{tabular}

WFNS = World Federation of Neurosurgical Societies.

Mean values are given with SDs.

be decided on the basis of available evidence. We incline to the view that clipping of the neck of the aneurysm is the more promising method." ${ }^{53}$ The authors stated, though, that carotid ligation still had a place in the treatment of supraclinoid ICA aneurysms, and in those cases where the aneurysm was very large and unsuitable for direct clipping.

With the development and popularization of the operating microscope and microsurgical techniques-after the pioneer works of Jacobson ${ }^{37}$ and Pool ${ }^{59}$ in the 1960 s-there was renewed enthusiasm for the direct clipping of paraclinoid aneurysms. . $^{2,110,17,25,32,33,54,61,67,82}$ The first description of a direct aneurysm suction decompression was published by French et al. in $1966 .{ }^{26}$ It consisted of aneurysm deflation by puncture and direct suction aspiration before ap- plication of silver clips at the aneurysm neck. In their 1968 publication, Drake et al. reported their experience with the treatment of 14 patients harboring carotid-ophthalmic aneurysms..$^{18}$ Nine of those patients $(64.3 \%)$ had other associated intracranial aneurysms. Half of the patients were treated by direct aneurysm occlusion using a Mayfield clip. Those authors were the first to recognize the importance of the anterior clinoidectomy for adequate proximal ICA control. A few years later, Benedetti et al. described their successful experience treating 6 patients with large carotid-ophthalmic aneurysms..$^{10}$ This 1975 study was also one of the first to describe the importance of temporary cervical carotid ligation for aneurysm deflation and primary clip reconstruction. In his landmark 1979 article on the surgical treatment of giant intracranial aneurysms, Charles Drake introduced several techniques that became standard of care for the treatment of those lesions: deep systemic hypotension, temporary occlusion using "weakened" Mayfield clips repetitively sprung open, forceps crushing technique (for atheromatous aneurysm necks), temporary trapping with aneurysm thrombectomy, use of fenestrated aneurysm clips, and tandem clip reconstruction of large aneurysm necks. ${ }^{18}$ Contemporary to Drake, Fox described a case of successful clip reconstruction of 2 mirror-image giant carotid-ophthalmic aneurysms in a 49-year-old woman who presented with SAH. In 2 separate craniotomies (one to treat each lesion), Fox described the principle of ICA trapping by cervical carotid ligature and a Heifetz clip just proximal to the posterior communicating artery. Both aneurysms were decompressed surgically and their domes were resected, with tandem aneurysm clips used for successful aneurysm obliteration. ${ }^{25}$

The suction decompression technique for treatment of large and giant aneurysms published by Eugene Flamm in 1981 was a refined modification of the initial work from French. The direct aneurysm puncture and suction aspiration was helpful, but it could result in aneurysm tear at its junction with the parent vessel, resulting in difficultto-control intraoperative bleeding. The introduction of an indirect system consisted of a 21-gauge butterfly scalp needle, and suction aspiration through its extension tubing, provided a more controlled aneurysm deflation and reduced the chances of irreparable damages to the aneurysm dome. It was rapidly adopted by other authors, with special application on the treatment of giant intracranial aneurysms. ${ }^{6,35,71}$ Nonetheless, Flamm's suction decompression technique had some limitations. It introduced a relatively cumbersome instrument (butterfly needle with tubing) into an already crowded operative field. It also restricted the final aneurysm neck dissection and clip application to a single-hand process, since the surgeon's nondominant hand would be occupied with aneurysm suction deflation. Some authors also reported occasional needle slippage out of the aneurysm dome puncture site, with a resultant inadvertent intraoperative bleeding at the critical moment of clip application..$^{35}$

\section{The Development of the Retrograde Suction Decompression Technique}

The following 3 paragraphs constitute the personal recollection of one of the senior authors (D.S.S.) regarding 
the events leading to the development of the RSD technique. In an attempt to preserve the impact that his personal statement on this topic has on the most avid neurosurgical historian listeners, it is transcribed below with minimal changes.

As we (H.H.B., D.S.S.) began to attract complex cerebrovascular cases to the University of Texas Southwestern Medical Center in the mid-1980s, we recognized that large and giant aneurysms - all of which were symptomatic by the time they were diagnosed - were especially problematic. Certainly, this was not an original observation. Our mentors-Drs. Charles G. Drake and Mahmut Gazi Yaşargil-had long since pointed out that the sheer size of these lesions, their almost-invariable extensive necks, and the combination of thick walls and intraluminal thrombus made successful direct surgical obliteration, even in their hands, very difficult. These problems were magnified at the skull base when the acquisition of proximal control of the parent ICA was often difficult; additionally, in those unusual cases when the intradural ICA could be exposed proximal to the aneurysm's neck, frequently there was insufficient room for both a proximal temporary clip, and several permanent clips were generally required for definitive neck closure. If one adds to those issues the need for arterial access to permit immediate post-clipping angiography, it would not come as a surprise that early on we became firm believers in preliminary cervical exposure of the carotid artery at and above the level of its bifurcation.

Unfortunately, more often than not, the extensive collateral supply to the intracranial ICA would prevent sufficient deflation of an ophthalmic segment ICA aneurysm with simple occlusion of the cervical ICA. It would fail to reduce flow or adequately reduce the volume of an early intraoperative rupture to a level consistent with further dissection and accurate final clip placement. However, cervical ICA temporary occlusion was the only technique we had available at that time. We would often double-team all those lesions; one of us almost always had obtained adequate cervical carotid exposure long before the other had begun aneurysmal dissection. As mentioned above, since we always planned to follow the aneurysm clip placement with an intraoperative angiography, we also always had the angiographic setup ready on the operating room back table.

As neurosurgeons know all too well, desperation (not necessity) is the mother of invention. H.H.B. was operating on a large, previously ruptured ophthalmic segment ICA aneurysm, with dome buried in the gyrus rectus. He had removed the entire anterior clinoid process when an early intraoperative rupture happened. The profuse bleeding couldn't be controlled with the usual maneuvers, and D.S.S. occluded the cervical internal carotid without appreciable effect, followed - not without some real trepidation - by the origin of the ECA [external carotid artery]; there had been reports of unilateral blindness attributed to this maneuver. Sadly, if anything, those steps seemed to actually increase the hemorrhage risk. It was a tense moment for everyone, and at that point one of us - still not clear who-suggested that aspirating blood from cervical ICA might help-it sure was not going to hurt. We were very fortunate that in this specific case the aneurysm beautifully deflated; I doubt we would have tried it again otherwise.

Giant aneurysms of the proximal ICA are characterized by 2 unique technical anatomical points. First, proximal ICA control is usually not possible intracranially without direct cavernous sinus exploration. Second, even with temporary cervical and intracranial ICA occlusions, brisk retrograde flow through the ophthalmic artery and cavern- ous ICA branches may be sufficient to prevent adequate aneurysm relaxation..$^{7}$ Not infrequently, the aneurysm dome is partially or completely obscured by the optic nerve, the ICA, or the anterior clinoid process. Part of the aneurysm neck may be located within the cavernous sinus. ${ }^{24}$ The Dallas RSD was developed to overcome some of those limitations. The cervical and communicating segment ICA temporary occlusions provide partial aneurysmal relaxation; it is significantly increased by RSD, with marked aneurysmal deflation (Fig. 3). This maneuver may transform a technically impossible clip reconstruction of a wide-neck giant aneurysm into a more controlled surgical procedure, by creating significant aneurysm relaxation and increased neck visualization. It also provides a direct method for intraoperative confirmation of aneurysm obliteration-and exclusion of a clip-induced stenosis of the parent vessel-by utilizing the cervical ICA access for cerebral angiography. The cervical carotid exposure and proximal ICA occlusion can be obtained concomitantly with the craniotomy approach and do not add significant length to the surgical procedure. Even in the cases where the need for cervical carotid temporary occlusion and RSD is uncertain, the cervical surgical site can be prepared and draped at the beginning of the case, and full cervical carotid exposure can be completely performed when needed within no more than 15 minutes.

In our original publication, 40 patients with giant paraclinoid ICA aneurysms were treated using the Dallas RSD technique; all aneurysms were successfully obliterated (Fig. 4). One complication was reported: a cervical ICA dissection occurred after a second intraoperative puncture of an atherosclerotic cervical carotid segment, requiring emergent endarterectomy. Since then, 124 patients have been treated at UTSW using the Dallas RSD technique, for an overall obliteration rate of $95.2 \%$. To our knowledge, those 164 patients constitute the largest institutional series on the use of the Dallas RSD technique for the treatment of paraclinoid aneurysms. One of the main criticisms raised against this technique was the supposedly high rate of cervical ICA injury and intracranial thromboembolic complications secondary to the direct ICA puncture. In our experience, the majority of the perioperative thromboembolic complications are secondary to the complexity of the paraclinoid aneurysm itself and not attributable to the technical steps involved in the Dallas RSD technique (data not shown). Atheromatous changes involving the aneurysm neck may result in parent vessel stenosis, dislodgement of intra-aneurysmal thrombus into the distal ICA intracranial circulation, or clip migration with residual aneurysm filling.

A few modifications of the original Dallas RSD technique have been proposed by different authors in an attempt to reduce the perceived risk associated with cervical ICA direct puncture. A superior thyroid artery cut-down may be fashioned for introduction of the catheter in a retrograde manner into the ICA. ${ }^{74,75} \mathrm{~A}$ direct cervical external carotid artery (ECA) puncture has also been described. ${ }^{22}$ By relocating the puncture site to the ECA circulation, those 2 techniques attempt to reduce the theoretical risk of cervical ICA dissection secondary to angiocatheter insertion. Inherent to both techniques, though, is the potential 

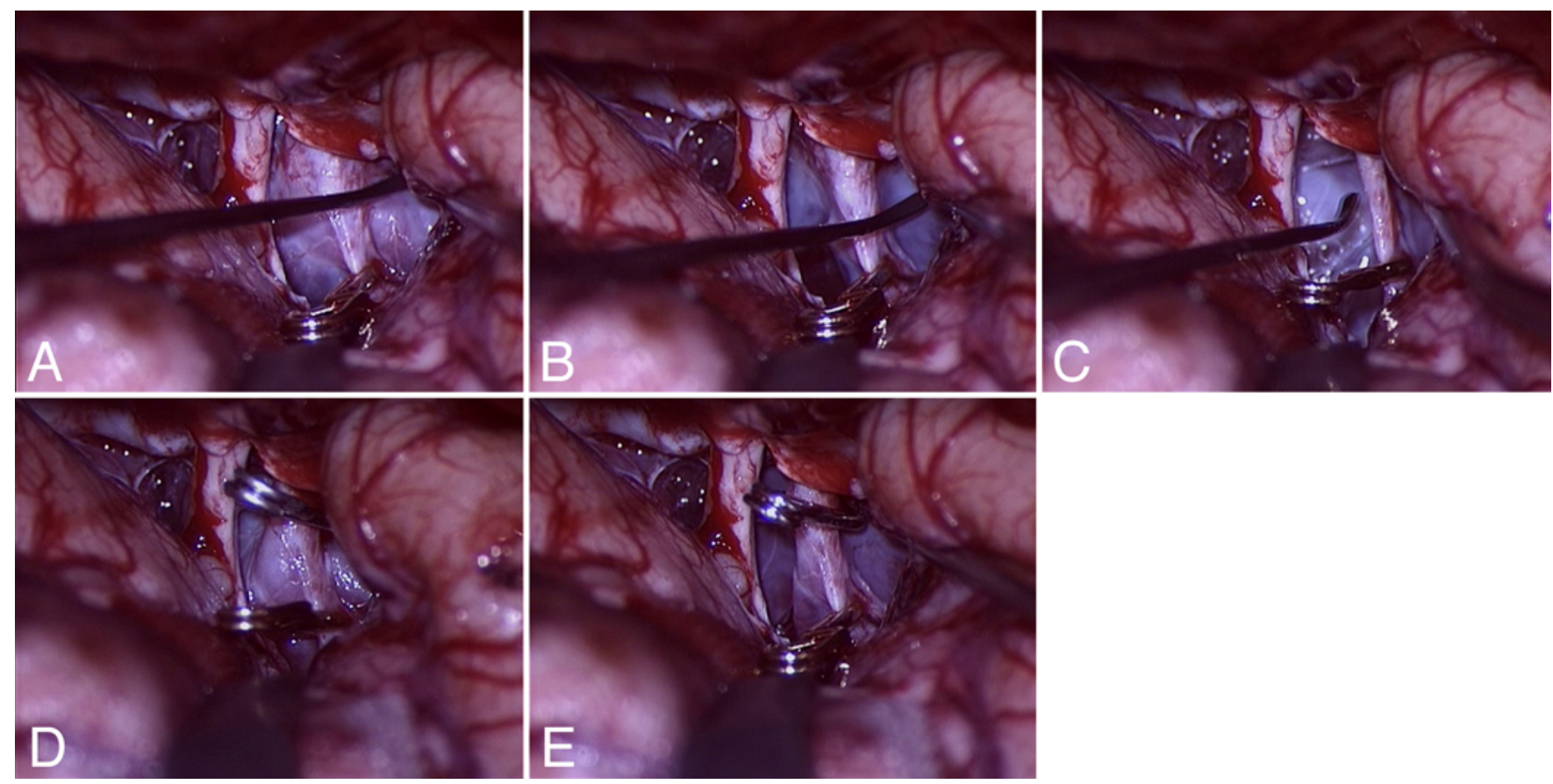

FIG. 3. Intraoperative microscope photographs of a patient presenting with a giant, unruptured inferiorly and posteriorly projecting paraclinoid ICA aneurysm. Right-sided pterional craniotomy, transsylvian approach. A: A temporary aneurysm clip has been placed at the distal supraclinoid ICA, proximal to the origin of the posterior communicating artery. Cervical carotid exposure and temporary occlusion was obtained concomitantly by the assistant surgeon (not shown). B and C: Retrograde suction decompression through cervical ICA access results in progressive and marked aneurysm deflation, allowing for excellent circumferential dissection corridors at the carotid-oculomotor (B) and optico-carotid (C) triangles. D: One fenestrated right-angled aneurysm clip has been applied proximally for partial paraclinoid ICA clip reconstruction. Note the interval aneurysm re-expansion with temporary interruption of the RSD. E: RSD is then restarted before application of final tandem clip construct with excellent aneurysm deflation and visualization of the residual ICA ventral and lateral walls. Figure is available in color online only.

catastrophic risk of retinal ischemic infarct. The occlusion of the ECA, coupled with simultaneous and continuous RSD of the ICA, may induce a central retinal artery ischemic interval, which-if profound and prolonged-may result in retinal infarction. Other authors have migrated the puncture site proximally into the common carotid artery. ${ }^{48,55,56,73}$ This modification avoids the potential risk of introducing a needle into a heavily calcified or atherosclerotic ICA segment.

The main advantage of the endovascular RSD technique is that it obviates the need for the cervical dissection and ICA exposure. Through a routine transfemoral approach, both proximal cervical ICA temporary occlusion and RSD can be obtained using a standard double-lumen balloon occlusion catheter. It also provides a fast route for endovascular balloon occlusion of the paraclinoid ICA segment at the level of the aneurysm neck..$^{19,69,76}$ For this purpose, a standard balloon occlusion microcatheter system could be advanced intracranially through the double-lumen balloon catheter positioned at the cervical ICA. This technique is particularly helpful in the cases where a partially thrombosed aneurysm is treated, since it can provide durable flow arrest during intra-aneurysmal thrombectomy. Direct paraclinoid ICA balloon occlusion is also helpful in the cases where intraoperative rupture occurs, because it can provide a more consistent hemostasis than simple trapping and retrograde suction decompression.

The development of flow-diverting stents (FDSs) has significantly modified the indications for surgical treatment of paraclinoid aneurysms. In several institutions, the benefits of a less-invasive procedure, shorter postoperative recovery time, and high long-term obliteration rates with relatively low rates of morbidity and mortality have transformed endovascular treatment of paraclinoid aneurysms into a first-line treatment. A recently published retrospective analysis of 127 consecutive patients harboring 160 ophthalmic segment aneurysms showed a complete occlusion rate at 18 months of $89.1 \%$. The rates were even higher for large and giant aneurysms (95.7\% and 100\%, respectively). ${ }^{31}$ Table 5 summarizes the FDS published data from 2009 through 2017, with a special focus on the large studies that specifically included high proportions of aneurysms involving the supraclinoid ICA. The pooled analysis of those studies identified 1392 supraclinoid ICA aneurysms treated with the use of an FDS. The overall occlusion rate was $83.8 \%$, with transient and permanent morbidity rates of $6.2 \%$ and $6.9 \%$, respectively.

Despite the understandable temptation, care should be taken when comparing those numbers described above with the ones obtained from the pooled analysis of the surgical treatment of paraclinoid aneurysms. The use of the RSD technique is a useful but not mandatory step for the treatment of those lesions, with other authors describing their experience in the treatment of paraclinoid aneurysms with the assistance of different techniques. ${ }^{11,13,34,42,47,66}$ A comparison between surgical and endovascular tech- 


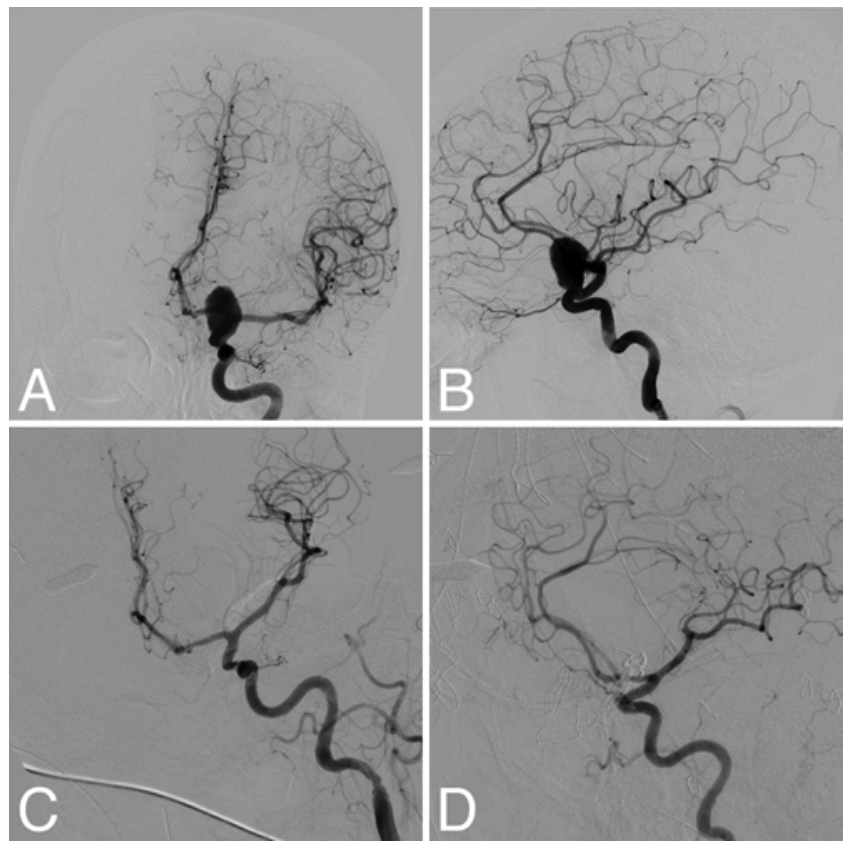

FIG. 4. A and B: Preoperative cerebral angiography of a giant, partially thrombosed paraclinoid ICA aneurysm presenting with progressive vision loss. Note that on the lateral views that the aneurysm neck is distal to the ophthalmic artery origin (B). Retrograde suction decompression technique was applied for aneurysm thrombectomy and primary clip reconstruction. C and D: Postoperative cerebral angiography on anteroposterior $(C)$ and lateral $(D)$ views show complete aneurysm obliteration and patency of the ophthalmic artery, with no stenosis of the paraclinoid ICA.

niques for treatment of those lesions should take those patients also into consideration. When one restricts the comparison exclusively to the RSD and FDS patients, the heterogeneity of the groups appears to preclude any meaningful evaluation. The limitations associated with the use of dual antiplatelet therapy, as well as the potential rate for early hemorrhage, is a major limitation of the use of FDS for the treatment of ruptured intracranial aneurysms. As seen in Table 5 , only $3.8 \%$ of the patients treated with an FDS presented with SAH. A recent systematic review showed a significantly higher overall complication rate in cases of ruptured intracranial aneurysms $(30.6 \%$ vs $14.6 \%$ for unruptured, OR 2.3) ${ }^{83}$ It is important to remember that the overall complication rate reported for FDS might be a misrepresentation, since only a few of the large FDS case series were exclusive for paraclinoid aneurysms. ${ }^{31,62,64}$ None of the 253 patients included in those 3 studies were treated during the acute presentation of a ruptured paraclinoid aneurysm.

This heterogeneity is also seen when analyzing aneurysm sizes. Only $8.1 \%$ of the aneurysms reported in the FDS studies were giant; overall, more than half of the aneurysms were small $(53.8 \%)$. The latter aneurysm size rarely requires the use of RSD technique for safer microsurgical clipping, and the morbidity and mortality rates associated with their surgical treatment are expectedly lower than the ones described in the current study. The smaller aneurysm sizes in the FDS data are directly related to the very low proportion of patients who presented with pre-

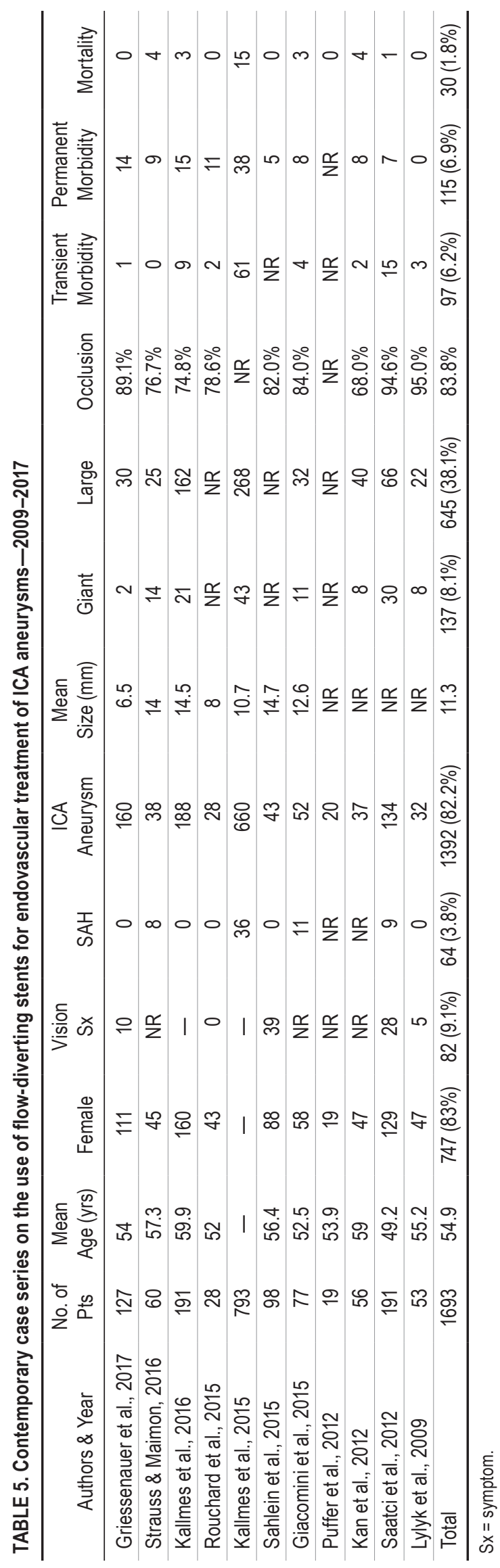


operative vision changes-9.1\%. This percentage includes also patients who presented with ophthalmoparesis/ophthalmoplegia secondary to direct compressive neuropathy, since distinguishing between these patients and those who presented with only poor visual acuity is often difficult in the FDS data. ${ }^{64}$ After extensive ophthalmological evaluations, one study found new ophthalmological complications in $39.3 \%$ of the 28 patients treated with FDS covering the origin of the ophthalmic artery. Other authors have described the need for surgical trapping and bypass for definitive treatment of an enlarging giant supraclinoid ICA aneurysm initially treated with FDS. ${ }^{1}$

\section{Pooled Analysis of the Literature}

Our current systematic review of the literature corroborates our institutional findings. Over the last 25 years, more than 500 patients were treated using the RSD technique (either open or endovascular), with an excellent overall obliteration rate $(95 \%)$ and extremely low rates of RSD-specific morbidity and mortality $(1.33 \%$ and $0.38 \%$, respectively). Good neurological outcomes were reported in $79.3 \%$ of the patients, despite the intrinsic complexity of large and giant aneurysms located at the proximal supraclinoid ICA. It is important to emphasize that this reported obliteration rate does not include the cases in which the aneurysm was successfully treated by primary ICA sacrifice with or without EC-IC (extracranial-intracranial) bypass. Contrary to the belief shared by some authors, those numbers suggest that RSD is a safe and highly effective technique that allows for primary clipping of complex aneurysms that would otherwise not be amenable to open treatment. The microsurgical treatment of large and giant paraclinoid ICA aneurysms also offers obvious advantages over exclusive endovascular treatment in patients presenting with visual deficits, since open surgery provides a durable method of decompression of the optic nerve and chiasm by aneurysm deflation.

The study population age and strong female representation were similar to what was observed in large series preceding the development of the RSD technique. $3,9,10,15,17$, $29,32,33,35,41,67,72$ Not unexpectedly, SAH (43.6\%) and vision loss $(25.3 \%)$ were the most common presenting symptoms. This high incidence of aneurysm rupture at presentation highlights the tendency for a much more aggressive natural history of large and giant paraclinoid aneurysms when compared with their smaller counterparts., , $^{4,51,72}$ Not infrequently, large and giant aneurysms are partially thrombosed at the time of diagnosis and present at least a theoretical risk of thromboembolic ischemia due to the dislodgement of small thrombotic fragments into the distal intracranial circulation. Despite this belief, our systematic review showed a relatively low incidence of transient ischemic attacks (TIAs) or ischemic strokes at the time of presentation (2.7\%).

Intraoperative angiography was used in $86.3 \%$ of the patients, with those numbers relatively lower on the Dallas RSD (79.2\%). In our opinion, this important intraoperative diagnostic tool should be mandatory in the surgical treatment of paraclinoid aneurysms. In several cases throughout our practice, we have found that a tandem clip reconstruction that appears adequate at microscopic inspection may in fact hide an overlooked incomplete neck clip occlusion, or significant stenosis of the paraclinoid ICA by the clip construct may be revealed by intraoperative angiography despite adequate indocyanine green (ICG) videoangiography or ICA Doppler ultrasound signals. Not infrequently, those situations require resuming temporary occlusion and clip reposition. Despite this often-complex vessel reconstruction process, the mean temporary occlusion time among all the RSD studies was not elevated (12.7 minutes).

Subgroup analysis of the different RSD techniques (Dallas RSD vs endovascular RSD) demonstrated similar obliteration rates and overall morbidity for the 2 RSD groups. However, the subgroup populations were very heterogeneous. The Dallas RSD subgroup was older, with significantly higher prevalence of giant and ruptured aneurysms. Despite treating theoretically more complex lesions, the long-term functional outcome was better in the Dallas RSD subgroup: the prevalence of long-term poor outcome was higher in the endovascular RSD subgroup, and there was a trend toward lower mortality in the Dallas RSD subgroup. More importantly, the prevalence of RSDrelated mortality was significantly higher in the endovascular RSD subgroup. The possible explanations for this unexpected advantage toward a Dallas RSD technique is multifactorial, and any in-depth analysis would be flawed by a population and selection bias demonstrated by the heterogeneity of both groups. Those results, though, are strong indicators for-if not outcome superiority-at least the noninferiority of the Dallas RSD compared with the endovascular RSD technique.

The current pooled analysis has several limitations. The retrospective nature of the pooled studies inserts inevitable selection bias into the final statistical analysis. In order to be as comprehensive as possible, high heterogeneity among the included studies was tolerated, but it also introduced significant publication bias due to wide variation on methodological aspects of each of the included studies. Only one study had patients that were treated with both RSD techniques. ${ }^{20}$ But even that study did not stratify its results based on the RSD technique used for each of their subgroups. The evolution of endovascular neurosurgery within the last 25 years was accompanied by improvements in the safety profiles of several neurointerventional techniques, but the contribution of this technological advancement into the reported results of each endovascular RSD study cannot be accurately extracted from the original studies. Lastly, several of the included studies had small sample sizes and could have contributed to an artificially better outcome report based on the file-drawer effect.

\section{Conclusions}

Since the initial studies by Walter Dandy, the surgical treatment of large and giant paraclinoid aneurysms has evolved tremendously. Several surgical techniques developed since the 1960s have contributed to a gradual but irreversible transition from primary cervical ICA ligation to direct aneurysm clip obliteration. The treatment of paraclinoid ICA aneurysms using the RSD technique is associated with high aneurysm obliteration rates, good 
long-term neurological outcome, and low rates of RSDrelated morbidity and mortality. Our pooled analysis of the RSD literature shows no evidence of a theoretical higher complication rate associated with a direct cervical carotid puncture (Dallas RSD). On a subgroup analysis comparing Dallas RSD and endovascular RSD, both groups achieved similar obliteration rates, but the Dallas RSD had lower RSD-related morbidity despite a higher frequency of large/ giant and ruptured aneurysms.

The reported results of these 2 surgical strategies represent important benchmarks to which future microsurgical and endovascular technologies (such as FDSs) should be compared for aneurysms of similar complexity.

\section{Acknowledgments}

The authors would like to thank Suzanne "Jorlam" Truex, medical illustrator, for her invaluable assistance in the creation of beautiful unique artistic drawings for this article.

\section{References}

1. Abla AA, Zaidi HA, Crowley RW, Britz GW, McDougall CG, Albuquerque FC, et al: Optic chiasm compression from mass effect and thrombus formation following unsuccessful treatment of a giant supraclinoid ICA aneurysm with the Pipeline device: open surgical bailout with STA-MCA bypass and parent vessel occlusion. J Neurosurg Pediatr 14:31-37, 2014

2. Albert FK, Forsting M, Aschoff A, Krieger D, Kunze S: Clipping of proximal paraclinoid aneurysm with support of the balloon-catheter "trapping-evacuation" technique. Technical note. Acta Neurochir (Wien) 125:138-141, 1993

3. Almeida GM, Shibata MK, Bianco E: Carotid-ophthalmic aneurysms. Surg Neurol 5:41-45, 1976

4. Arnautović KI, Al-Mefty O, Angtuaco E: A combined microsurgical skull-base and endovascular approach to giant and large paraclinoid aneurysms. Surg Neurol 50:504-520, 1998

5. Barrow DL, Alleyne C: Natural history of giant intracranial aneurysms and indications for intervention. Clin Neurosurg 42:214-244, 1995

6. Batjer HH, Frankfurt AI, Purdy PD, Smith SS, Samson DS: Use of etomidate, temporary arterial occlusion, and intraoperative angiography in surgical treatment of large and giant cerebral aneurysms. J Neurosurg 68:234-240, 1988

7. Batjer HH, Kopitnik TA, Giller CA, Samson DS: Surgery for paraclinoidal carotid artery aneurysms. J Neurosurg 80:650-658, 1994

8. Batjer HH, Samson DS: Retrograde suction decompression of giant paraclinoidal aneurysms. Technical note. J Neurosurg 73:305-306, 1990

9. Benedetti A, Curri D: Direct attack on carotid ophthalmic and large internal carotid aneurysms. Surg Neurol 8:49-54, 1977

10. Benedetti A, Curri D, Carbonin C, Rubini L: On the radical treatment of a large carotid-ophthalmic aneurysm: case report. J Neurosurg Sci 19:176-180, 1975

11. Cawley CM, Zipfel GJ, Day AL: Surgical treatment of paraclinoid and ophthalmic aneurysms. Neurosurg Clin N Am 9:765-783, 1998

12. Chen SF, Kato Y, Subramanian B, Kumar A, Watabe T, Imizu S, et al: Retrograde suction decompression assisted clipping of large and giant cerebral aneurysms: our experience. Minim Invasive Neurosurg 54:1-4, 2011

13. Colli BO, Carlotti CG, Assirati JA, Abud DG, Amato MCM, Dezena RA: Results of microsurgical treatment of paraclinoid carotid aneurysms. Neurosurg Rev 36:99-115, 2013

14. Dandy WE: The surgical treatment of intracranial aneurysms of the internal carotid artery. Ann Surg 114:336-340, 1941
15. Day AL: Aneurysms of the ophthalmic segment. A clinical and anatomical analysis. J Neurosurg 72:677-691, 1990

16. Dehdashti AR, Le Roux A, Bacigaluppi S, Wallace MC: Long-term visual outcome and aneurysm obliteration rate for very large and giant ophthalmic segment aneurysms: assessment of surgical treatment. Acta Neurochir (Wien) 154:43-52, 2012

17. Drake CG: Giant intracranial aneurysms: experience with surgical treatment in 174 patients. Clin Neurosurg 26:12-95, 1979

18. Drake CG, Vanderlinden RG, Amacher AL: Carotid-ophthalmic aneurysms. J Neurosurg 29:24-31, 1968

19. Elhammady MS, Nakaji P, Farhat H, Morcos JJ, Aziz-Sultan MA: Balloon-assisted clipping of a large paraclinoidal aneurysm: a salvage procedure. Neurosurgery 65:E1210-E1211, 2009

20. Eliava SS, Filatov YM, Yakovlev SB, Shekhtman OD, Kheireddin AS, Sazonov IA, et al: Results of microsurgical treatment of large and giant ICA aneurysms using the retrograde suction decompression (RSD) technique: series of 92 patients. World Neurosurg 73:683-687, 2010

21. Fahlbusch R, Nimsky C, Huk W: Open surgery of giant paraclinoid aneurysms improved by intraoperative angiography and endovascular retrograde suction decompression. Acta Neurochir (Wien) 139:1026-1032, 1997

22. Fan YW, Chan KH, Lui WM, Hung KN: Retrograde suction decompression of paraclinoid aneurysm - a revised technique. Surg Neurol 51:129-131, 1999

23. Flamm ES: Suction decompression of aneurysms. Technical note. J Neurosurg 54:275-276, 1981

24. Fox JL: Microsurgical treatment of ventral (paraclinoid) internal carotid artery aneurysms. Neurosurgery 22:32-39, 1988

25. Fox JL: Multiple giant aneurysms. Surg Neurol 12:147-151, 1979

26. French LA, Chou SN, Story JL, Schultz EA: Aneurysm of the anterior communicating artery. J Neurosurg 24:1058-1062, 1966

27. Fulkerson DH, Horner TG, Payner TD, Leipzig TJ, Scott JA, Denardo AJ, et al: Endovascular retrograde suction decompression as an adjunct to surgical treatment of ophthalmic aneurysms: analysis of risks and clinical outcomes. Neurosurgery 64 (3 Suppl):ons107-ons112, 2009

28. Gao X, Yu C, Wang X, Zhang H, Li Z, Zhu T, et al: Microsurgical treatment of large and giant paraclinoid carotid aneurysms using a revised endovascular suction decompression technique with Invatec Mo.Ma device. J Clin Neurosci 33:264-268, 2016

29. Gelber BR, Sundt TM Jr: Treatment of intracavernous and giant carotid aneurysms by combined internal carotid ligation and extra- to intracranial bypass. J Neurosurg 52:1-10, 1980

30. Giacomini L, Piske RL, Baccin CE, Barroso M, Joaquim AF, Tedeschi H: Neurovascular reconstruction with flow diverter stents for the treatment of 87 intracranial aneurysms: clinical results. Interv Neuroradiol 21:292-299, 2015

31. Griessenauer CJ, Piske RL, Baccin CE, Pereira BJA, Reddy AS, Thomas AJ, et al: Flow diverters for treatment of 160 ophthalmic segment aneurysms: evaluation of safety and efficacy in a multicenter cohort. Neurosurgery 80:726-732, 2017

32. Guidetti B, La Torre E: Carotid-ophthalmic aneurysms. A series of 16 cases treated by direct approach. Acta Neurochir (Wien) 22:289-304, 1970

33. Guidetti B, La Torre E: Management of carotid-ophthalmic aneurysms. J Neurosurg 42:438-442, 1975

34. Hauck EF, Wohlfeld B, Welch BG, White JA, Samson D: Clipping of very large or giant unruptured intracranial aneurysms in the anterior circulation: an outcome study. J Neurosurg 109:1012-1018, 2008 
35. Heros RC, Nelson PB, Ojemann RG, Crowell RM, DeBrun G: Large and giant paraclinoid aneurysms: surgical techniques, complications, and results. Neurosurgery 12:153163,1983

36. Hoh DJ, Larsen DW, Elder JB, Kim PE, Giannotta SL, Liu CY: Novel use of an endovascular embolectomy device for retrograde suction decompression-assisted clip ligation of a large paraclinoid aneurysm: technical case report. Neurosurgery 62 (5 Suppl 2):ONSE412-ONSE414, 2008

37. Jacobson JH II, Wallman LJ, Schumacher GA, Flanagan M, Suarez EL, Donaghy RM: Microsurgery as an aid to middle cerebral artery endarterectomy. J Neurosurg 19:108-115, 1962

38. Kallmes DF, Brinjikji W, Boccardi E, Ciceri E, Diaz O, Tawk R, et al: Aneurysm Study of Pipeline in an Observational Registry (ASPIRe). Intervent Neurol 5:89-99, 2016

39. Kallmes DF, Hanel R, Lopes D, Boccardi E, Bonafé A, Cekirge S, et al: International retrospective study of the Pipeline Embolization Device: a multicenter aneurysm treatment study. AJNR Am J Neuroradiol 36:108-115, 2015 (Erratum in AJNR Am J Neuroradiol 36:E39-E40, 2015)

40. Kan P, Siddiqui AH, Veznedaroglu E, Liebman KM, Binning MJ, Dumont TM, et al: Early postmarket results after treatment of intracranial aneurysms with the Pipeline embolization device: a U.S. multicenter experience. Neurosurgery 71:1080-1088, 2012

41. Kothandaram P, Dawson BH, Kruyt RC: Carotid-ophthalmic aneurysms. A study of 19 patients. J Neurosurg 34:544-548, 1971

42. Li J, Lan ZG, Liu Y, He M, You C: Large and giant ventral paraclinoid carotid aneurysms: surgical techniques, complications and outcomes. Clin Neurol Neurosurg 114:907-913, 2012

43. Ljunggren B, Sharma S, Fodstad H: History and epidemiology of SAH and cerebrovascular malformaitons, in Pasqualin A, Da Pian R (eds): New Trends in Management of Cerebrovascular Malformations. Vienna: Springer Vienna, 1994, pp 3-15

44. Locksley HB: Natural history of subarachnoid hemorrhage, intracranial aneurysms and arteriovenous malformations. J Neurosurg 25:219-239, 1966

45. Lonjon M, Pennes F, Sedat J, Bataille B: Epidemiology, genetic, natural history and clinical presentation of giant cerebral aneurysms. Neurochirurgie 61:361-365, 2015

46. Lylyk P, Miranda C, Ceratto R, Ferrario A, Scrivano E, Luna $\mathrm{HR}$, et al: Curative endovascular reconstruction of cerebral aneurysms with the pipeline embolization device: the Buenos Aires experience. Neurosurgery 64:632-643, N6, 2009

47. Matano F, Tanikawa R, Kamiyama H, Ota N, Tsuboi T, Noda $\mathrm{K}$, et al: Surgical treatment of 127 paraclinoid aneurysms with multifarious strategy: factors related with outcome. World Neurosurg 85:169-176, 2016

48. Mattingly T, Kole MK, Nicolle D, Boulton M, Pelz D, Lownie SP: Visual outcomes for surgical treatment of large and giant carotid ophthalmic segment aneurysms: a case series utilizing retrograde suction decompression (the "Dallas technique"). J Neurosurg 118:937-946, 2013

49. Mizoi K, Takahashi A, Yoshimoto T, Fujiwara S, Koshu $\mathrm{K}$ : Combined endovascular and neurosurgical approach for paraclinoid internal carotid artery aneurysms. Neurosurgery 33:986-992, 1993

50. Moher D, Liberati A, Tetzlaff J, Altman DG: Preferred reporting items for systematic reviews and meta-analyses: the PRISMA statement. BMJ 339:b2535, 2009

51. Murayama Y, Takao H, Ishibashi T, Saguchi T, Ebara M, Yuki I, et al: Risk analysis of unruptured intracranial aneurysms: prospective 10-year cohort study. Stroke 47:365-371, 2016

52. Ng PY, Huddle D, Gunel M, Awad IA: Intraoperative endo- vascular treatment as an adjunct to microsurgical clipping of paraclinoid aneurysms. J Neurosurg 93:554-560, 2000

53. Norlen G, Olivecrona $\mathrm{H}$ : The treatment of aneurysms of the circle of Willis. J Neurosurg 10:404-415, 1953

54. Nutik S: Carotid paraclinoid aneurysms with intradural origin and intracavernous location. J Neurosurg 48:526-533, 1978

55. Otani N, Wada K, Toyooka T, Fujii K, Ueno H, Tomura S, et al: Retrograde suction decompression through direct puncture of the common carotid artery for paraclinoid aneurysm. Acta Neurochir Suppl 123:51-56, 2016

56. Otani N, Wada K, Toyooka T, Fujii K, Ueno H, Tomura S, et al: Usefulness of suction decompression method combined with extradural temporopolar approach during clipping of complicated internal carotid artery aneurysm. World Neurosurg 90:293-299, 2016

57. Parkinson RJ, Bendok BR, Getch CC, Yashar P, Shaibani A, Ankenbrandt W, et al: Retrograde suction decompression of giant paraclinoid aneurysms using a No. 7 French ballooncontaining guide catheter. Technical note. J Neurosurg 105:479-481, 2006

58. Polevaya NV, Kalani MYS, Steinberg GK, Tse VCK: The transition from hunterian ligation to intracranial aneurysm clips: a historical perspective. Neurosurg Focus 20(6):E3, 2006

59. Pool JL, Colton RP: The dissecting microscope for intracranial vascular surgery. J Neurosurg 25:315-318, 1966

60. Puffer RC, Kallmes DF, Cloft HJ, Lanzino G: Patency of the ophthalmic artery after flow diversion treatment of paraclinoid aneurysms. J Neurosurg 116:892-896, 2012

61. Punt J: Some observations on aneurysms of the proximal internal carotid artery. J Neurosurg 51:151-154, 1979

62. Rouchaud A, Leclerc O, Benayoun Y, Saleme S, Camilleri Y, D'Argento F, et al: Visual outcomes with flow-diverter stents covering the ophthalmic artery for treatment of internal carotid artery aneurysms. AJNR Am J Neuroradiol 36:330336, 2015

63. Saatci I, Yavuz K, Ozer C, Geyik S, Cekirge HS: Treatment of intracranial aneurysms using the pipeline flow-diverter embolization device: a single-center experience with longterm follow-up results. AJNR Am J Neuroradiol 33:14361446, 2012

64. Sahlein DH, Fouladvand M, Becske T, Saatci I, McDougall CG, Szikora I, et al: Neuroophthalmological outcomes associated with use of the Pipeline Embolization Device: analysis of the PUFS trial results. J Neurosurg 123:897-905, 2015

65. Scott JA, Horner TG, Leipzig TJ: Retrograde suction decompression of an ophthalmic artery aneurysm using balloon occlusion. Technical note. J Neurosurg 75:146-147, 1991

66. Seifert V, Güresir E, Vatter H: Exclusively intradural exposure and clip reconstruction in complex paraclinoid aneurysms. Acta Neurochir (Wien) 153:2103-2109, 2011

67. Sengupta RP, Gryspeerdt GL, Hankinson J: Carotid-ophthalmic aneurysms. J Neurol Neurosurg Psychiatry 39:837853,1976

68. Shimizu T, Naito I, Aihara M, Fujimaki H, Asakura K, Miyamoto N, et al: Visual outcomes of endovascular and microsurgical treatment for large or giant paraclinoid aneurysms. Acta Neurochir (Wien) 157:13-20, 2015

69. Skrap M, Petralia B, Toniato G: Temporary balloon occlusion during the surgical treatment of giant paraclinoid and vertebrobasilar aneurysms. Acta Neurochir (Wien) 152:435-442, 2010

70. Strauss I, Maimon S: Silk flow diverter in the treatment of complex intracranial aneurysms: a single-center experience with 60 patients. Acta Neurochir (Wien) 158:247-254, 2016

71. Sugita K, Kobayashi S, Kyoshima K, Nakagawa F: Fenestrated clips for unusual aneurysms of the carotid artery. $\mathbf{J}$ Neurosurg 57:240-246, 1982 
72. Sundt TM Jr, Piepgras DG: Surgical approach to giant intracranial aneurysms. Operative experience with 80 cases. J Neurosurg 51:731-742, 1979

73. Takahashi T, Suzaki N, Tsugane S, Yamauchi K, Takada S: Suction decompression methods for giant internal carotid ophthalmic aneurysms by using revised double lumen balloon catheters. Acta Neurochir Suppl 103:9-10, 2008

74. Takeuchi S, Tanikawa R, Goehre F, Hernesniemi J, Tsuboi $\mathrm{T}$, Noda K, et al: Retrograde suction decompression for clip occlusion of internal carotid artery communicating segment aneurysms. World Neurosurg 89:19-25, 2016

75. Tamaki N, Kim S, Ehara K, Asada M, Fujita K, Taomoto K, et al: Giant carotid-ophthalmic artery aneurysms: direct clipping utilizing the "trapping-evacuation" technique. J Neurosurg 74:567-572, 1991

76. Thorell W, Rasmussen P, Perl J, Masaryk T, Mayberg M: Balloon-assisted microvascular clipping of paraclinoid aneurysms. Technical note. J Neurosurg 100:713-716, 2004

77. Tytus JS, Ward AA Jr: The effect of cervical carotid ligation on giant intracranial aneurysms. J Neurosurg 33:184-190, 1970

78. Vega-Basulto S: Técnica de descompresión-succión retrógada en los aneurismas paraclinoideos. Rev Neurol 37:312-317, 2003

79. Vega-Basulto SD, Silva-Adan S, Laserda-Gallardo A, Penones-Montero R, Varela-Hernandez A: Aneurismas intracraneales supratentoriales gigantes. Analisis de 22 casos. Neurocirugía 14:16-24, 2003

80. Xu BN, Sun ZH, Jiang JL, Wu C, Zhou DB, Yu XG, et al: Surgical management of large and giant intracavernous and paraclinoid aneurysms. Chin Med J (Engl) 121:1061-1064, 2008
81. Xu BN, Sun ZH, Romani R, Jiang JL, Wu C, Zhou DB, et al: Microsurgical management of large and giant paraclinoid aneurysms. World Neurosurg 73:137-146, e17, e19, 2010

82. Yasargil MG, Fox JL: The microsurgical approach to intracranial aneurysms. Surg Neurol 3:7-14, 1975

83. Zhou G, Su M, Yin YL, Li MH: Complications associated with the use of flow-diverting devices for cerebral aneurysms: a systematic review and meta-analysis. Neurosurg Focus 42(6):E17, 2017

\section{Disclosures}

The authors report no conflict of interest concerning the materials or methods used in this study or the findings specified in this paper.

\section{Author Contributions}

Conception and design: all authors. Acquisition of data: Flores. Analysis and interpretation of data: Flores. Drafting the article: Flores, White. Critically revising the article: all authors. Reviewed submitted version of manuscript: all authors. Approved the final version of the manuscript on behalf of all authors: Flores. Statistical analysis: Flores. Administrative/technical/material support: Samson. Study supervision: all authors.

\section{Correspondence}

Bruno C. Flores: University of Texas Southwestern Medical Center, Dallas, TX.bruno.flores@yahoo.com. 